March - 2007

\title{
Impact of ICTs on Open and Distance Learning in a Developing Country Setting: The Philippine experience
}

\author{
Melinda dela Pena-Bandalaria \\ University of the Philippines Open University
}

\begin{abstract}
The influence of the information and communication technologies (ICTs) in open and distance learning (ODL) in a developing country, the Philippines, is critically evaluated in this paper. Specifically, this paper examines how ICTs have influenced or shaped the development of ODL in this country. Also examined are the different stages or generations of distance education (DE) in the Philippines, which are characterized mainly by the dominant technology used for the delivery of instructional content and student support services. The different ICTs being used in ODL and their specific applications to the various facets of this mode of delivery are also described. Also included is an examination on how quality of education is ensured in a technology-driven system of teaching and learning, which includes, among others, the employment of the 'quality circle approach' in the development of courses and learning packages, and the provision of appropriate technologies to perform academic processes and achieve institutional goals. Experiences of the various universities in the Philippines are also cited in this paper. Lessons have been drawn from the ODL experience to guide educators from other developing countries.
\end{abstract}

Keywords: Open and distance learning; distance education; digital divide; information and communication technologies; developing countries; Philippines; SMS; mobile phone; mobile learning; ubiquitous learning; e-learning

\section{Introduction}

In a developing country like the Philippines where the 'digital divide' is more the rule than the exception, delivering instruction through the distance mode presents a significant challenge to educators. In a nation where the concern of most people is meeting their basic need for food, clothing, and shelter, access to information and communication technologies (ICT), especially the most modern ones, is very low on their list of priorities - and oftentimes, not considered a priority at all.

Nonetheless, ICT has had a major impact on open and distance learning (ODL) in the Philippines. More than the availability of these technologies, issues such as geographical location, lack of knowledge and skills to use ICT, and financial constraints, are major considerations in deciding what ICT to use and in what combination. Indeed, the use of a particular ICT must not only 
address certain pedagogical concerns, it must aim to bridge the digital divide and democratize access to quality education.

Experience has shown that when a decision has been made to use a technology in ODL, this decision influences not only the teaching and learning environment, it leads to the development of new cultures, concepts, and understanding. Put simply, the introduction of ICT can alter and raise expectation among users and institutions alike.

This paper discusses how ICT influenced the development and implementation of ODL in the Philippines. It also describes specific ICT and their applications in ODL, and evaluates the overall influence of ICT within ODL contexts in the Philippines.

\section{Development of ODL and e-Learning in the Philippines}

ODL and e-Learning in the Philippines had undergone major transformation in both form and content. More than five decades has witnessed major phases or stages of ODL development, based on the dominant technology in use at the time. Just like any other evolutionary process, it is very hard to definitively identify the end or beginning points of specific stages, as use of older with newer DE technologies tend to overlap and blur the boundaries. Nonetheless, the main concern has always been the pedagogy used, and not the technology itself per say. As such, one can view the development of DE in the Philippines as simply another 'classic case of necessity,' wherein educators experimented and explored various forms of ICT alone or in convergence with other more established forms of delivery to address pressing societal concerns and achieve academic and institutional goals.

The development of ODL in the Philippines has undergone four general stages or generations. Unlike other countries, the root of ODL in the Philippines was not print, nor even correspondence. On the contrary, radio was the first ODL instrument. Early ODL in the Philippines - which were radio programs designed, developed, and implemented by Filipinos for the Filipino people - consisted of informal, non-credit courses offered in the area of agriculture.

\section{First generation of $\mathrm{DE}$ in the Philippines}

The earliest documented effort of ODL in the Philippines was the Farmers' School-on-the-Air (FSA). The first FSA was aired in 1952 in the province of Iloilo, over a one-kilowatt radio station (Tan, 1971, as cited by Flor, 1995). A program entitled Tips on Farming and Community Development, which was broadcast in 1952 over a period of six months, served approximately 150 students scattered throughout the province.

The FSA-format was adopted by other radio stations and government agencies who aimed to teach different segments of Filipino society lessons they deemed necessary to improve Filipinos' standard of living. A sustained use of radio for instruction in the schools-on-the-air (SOA) format was accomplished by DZLB, a radio station managed by the University of the Philippines Los Banos (UPLB), which itself was a constituent unit of the University of the Philippines (UP), the nation's premiere university. Lessons, which aimed to educate farmers, out-of-school youths, housewives, and others living in rural areas were aired starting in 1967. To date, DZLB has aired more than 32 SOA topics and has graduated over 14,000 students in this mode of learning (Flor, 1995). 
The non-formal courses delivered through FSAs/ SOAs was the forerunner of modern distance education in the Philippines. As such, radio can be viewed as the First Generation DE in the Philippines.

\section{Second generation of $\mathrm{DE}$ in the Philippines}

Recognizing the potential of DE for continuing education of various professional groups, many traditional universities started offering their graduate degree programs via DE methods, which relied mostly on print-based instructional materials supplemented with occasional face-to-face tutorials facilitated by a university-trained tutor. This is the Second Generation Distance Education. In this second generation, lessons were typically contained in a set of print-based learning materials supplemented by face-to-face tutorials. However, these tutorials evolved to be more a venue for academic consultations and clarifications about the lessons, than covering the subject matter itself. As such, these regularly scheduled face-to-face meetings served as a:

- Formally scheduled consultation between the students and the university

- Place for students to undertake various transactions with the university

- Venue for socialization with fellow DE students

In essence, DE face-to-face tutorials had evolved into an informal system of 'student support,' and not a forum for the actual delivery of instructional content per say. Moreover, these 'tutorials' were never deemed compulsory; it was up to the student to decide for themselves whether to participate or not.

In the case of the University of the Philippines' Open University, its second generation DE was supplemented with 'radio' to deliver instructional content, which in itself is evidence of the overlapping practice left over from first generation DE. Experiments and initiatives on the use of television to supplement print materials also took place during the second generation of DE development in the Philippines, again showing that these generations are not so clear-cut and easy to define.

\section{Third generation of $\mathrm{DE}$ in the Philippines}

The third generation of DE in the Philippines saw the convergence of several key factors: 1) growing need for flexible learning, anytime, anywhere; 2) increased availability and access to new ICT; and 3) growing demand of geographically dispersed professional groups seeking access to flexible, lifelong learning opportunities. To address these emerging societal demands, instructional contents were primarily delivered in print-based formats (where instructional design is essential), supplemented with lesson components typically delivered in convenient audio and/ or video formats.

The need to explore alternative methods of delivering DE educational opportunities, however, soon became necessary, particularly when various professional groups in the Philippines were soon demanding flexibly delivered, full degree programs. However, because the Philippines is actually a country comprised of 7,107 islands, many Filipino learners cannot easily access universities main campuses and, in many instances, even their satellite campuses and learning centers. Moreover, most potential students work full time and must juggle family responsibilities 
in addition. As such, many Filipinos are not in a position to attend regularly scheduled classes during regular hours. Clearly, this growing demand for DE had to be met, because with without it, many Filipinos would simply be turned away. To overcome logistics of travel, DE enhanced with ICT for delivery of information rich learning opportunities, became an option. However, this reality put many universities in a financial quandary: they either stayed as they are, and lose this potential body of student, or they had to scrape up enough money to invest in ICT needed to serve these large, yet remote student populations. Thus, third generation DE can be defined as an stage in which Filipino educational providers sought to incorporate ICTs to support their students studying at a distance. As such, the third generation of DE saw the introduction of online tutorials that aimed to help learners. Teleconferences, facilitated by one tutor, became the primary mode of DE delivery for this type of interaction between students and teachers.

It should be noted, even in the third generation, universities' learning centers continued to play an important role in delivery of various administrative and pedagogical processes, such as enrollment, places where face-to-face tutorials were held, and other types of administrative support. In sum, university learning centers continued to serve as the DE institution's physical presence in various areas, centralized buildings wherein students could avail themselves of services they expected from their university.

\section{Fourth generation of $\mathrm{DE}$ in the Philippines}

Fourth generation DE can be aptly described using terms e-Learning (electronic learning), mLearning (mobile learning), and u-Learning (ubiquitous learning). The fourth generation can also be viewed as an 'empowered phase.' For teachers, the use of ICTs helped enhance their skills and knowledge. For students, use of ICTs enabled them to assert more control over their learning environment, specifically the 'how,' the 'when,' and the 'where,' and sometimes even the 'what' they will learn. Both students and teachers now have more flexibility to shape and structure their learning/ teaching environment to take full advantage of fellow participants' prior experiences. This dynamic of 'sharing prior knowledge and skills and contextualizing within the course materials' makes the educational experience far richer and more conducive to critical and higherorder thinking.

University learning centers' have also been transformed during the fourth generation of DE in the Philippines. Learning centers have become somewhat redundant, often viewed as a 'fall-back option' for administrative processes like registration, which are also offered online, 24/7. The major functions of the university learning centers, therefore, have been scaled back to being mere 'testing centers,' course materials distribution and pick-up points, a place for submitting assignments in hard copy, and submission centers of course requirements. In point form, the events that ushered in this current, fourth generation of DE in the Philippines are:

1. Increasing numbers of students found it impractical to use the conventional system of doing DE. Instead, they now use ICTs to supplement their new, independent, studentcentered learning styles.

2. More and more professionals in the Philippines found it necessary to upgrade their skills and knowledge to remain competitive. Earlier generations of DE, however, did not serve them well. Use of ICT now allow universities to reach many lifelong learners from the professional ranks at a distance, including many learners living outside the Philippines. 
3. The proliferation of Internet cafés has dramatically increased access throughout the Philippines. Indeed, the reality is that telephone lines are still not available to the majority of Filipinos, so many cannot access the Internet from home or even their offices. Internet cafés, therefore, have become a lucrative business that addresses growing demand for Internet access across the Philippines. As such, there has been an explosion of Internet cafés, particularly in urban areas. Competition among these small businesses is fierce and as a result, prices have dropped. Today, Internet cafés serve as venues for DE students who seek to access their online course materials or virtual classrooms.

4. The availability of hardware and software technologies, such as threaded discussion groups, RSS feeds, bulletin boards, online project submissions and quizzes, chats, Webbrowsing and safaris, and access to the World Wide Web, has extended the learning environment beyond the traditional brick and mortar campuses. And as prices drop for ICT, and as increased affordability of DE prevails through economies of scale, online teaching and learning will become increasingly feasible for large segments of the Filipino population seeking to access the personal, social, and economic benefits of lifelong learning.

So, while each successive generation of DE and ODL can be seen to be shaped by the primary technology used to deliver instructional content and learner support services at that particular point in time, several new questions must be asked as we view the dawn of the fourth generation of DE in the Philippines. Does the use of ICTs ensure that all Filipinos have access? Is the use of ICTs putting some Filipinos at a disadvantage?

\section{ICTs and ICT Applications in ODL in the Philippines}

ICTs used to support ODL can be classified into two main categories, the first being hardware and second being, software. The hardware currently in use are roughly the same among all Filipino institutions: radio, television, telephone (land, mobile, fax, Voice over Internet Protoco or VoIP ), and computers. ICTs have now converged thanks to recent advances and enhancements made to the infrastructure, such as the laying of fiber optic cables and satellite and microwave transmission facilities. What differ, however, are the levels of use and applications of specific hardware technologies and purpose driving their use.

Much variation can be observed in the ICT software components needed to support fourth generation DE. Such DE software tends to be customized to address variables such as: specific applications or purpose for which it will be used; the combination of hardware used to support DE applications; and features that need to be incorporated to meet users' needs. Customized forms of software is typically evident in the form of learning management systems (LMS) that are used to simulate classroom settings and facilitate academic discussions/ interactions. LMS are often meshed with other, pre-existing technologies such as databases and digital libraries.

Thus, various forms of LMS and their related hard- and software-components necessitates the formulation of appropriate polices, processes, and procedures that must align with preexisting policies, processes, and procedures - all of which must work in concert to support the smooth operation of the technology.

Use of ICT hardware has been greatly influenced by two factors: 1) access, and 2) cost of access. Access to ICTs can be viewed along two sub-factors: 1) physical access to the technology, and 2) pre-requisite skills one needs to use this technology effectively. One key indicator of 'physical 
access' in the Philippines is the level or rate of ownership. For example, most Filipino households and businesses own a radio, television, audiocassette, and/ or VHS/ VCD/ DVD player. Indeed, such technologies are very common. Moreover, because very little skill is required to operate these technologies, their use is only limited by the cost of the hardware itself and electricity needed to power it.

On the other hand, access to the Internet is determined by several sub-factors: 1) the physical access which, 2) is determined by the availability of the computer hardware and telephone; and 3) the skills needed to use the computer and access the Internet. The good news is that computer ownership in the Philippines is rapidly increasing. However, significant improvements must be made in the Philippines' telephone infrastructure before these computers can really be said to be 'connected' (i.e., installation of fiber optic cables, microwave transmissions and submarine cables to reach the 7,107 islands). Put simply, the landline telephone infrastructure in the Philippines is not very robust, and as a result, few Filipinos can access telephone services. Moreover, in recent years the landline telephone infrastructure in the Philippines has actually been in decline (Tibay, 2004). Some suggest that this decline can likely be attributed to the introduction of cellular mobile telephones, which are more affordable, accessible, practical, and hence, ubiquitous. So, even though there has been a marked decline in the Philippine's landline telephone infrastructure, there has been a marked increase in the number of registered Internet Service Providers in the Philippines' larger cities (Tibay, 2004). Again, this is manifest in the rapid proliferation of Internet cafés, which are helping to narrow the digital divide.

According to an article published in the Metropolitan Times (31, December, 2003) the main Internet access points for younger Filipinos are Internet cafés, while, the main access points for older Filipinos (age 30-60) are their offices and homes. Main purpose for 'Internet access' was for business (50\%), followed by personal use (41\%). The most popular Internet activity is sending and receiving email, followed by surfing/ browsing, chatting, and file download (Metropolitan Times, 31 December 2003). There was no mention of 'education' at all in this article, which in itself implies the recent emergence of e-Learning in the Philippines as a very new, alternative method of educational delivery.

Cellular mobile telephone use in the Philippines has enjoyed phenomenal growth. The number of cell phone subscribers has exploded. As a result, the Philippines has since been called the short messaging service (SMS) capital of the world, with SMS becoming an integral part in the Filipinos' communicative lifestyle. There are now more mobile phone subscribers, than fixedlandline telephone subscribers in the Philippines. By the dawn of 2006, the Philippines had 40 million mobile phone subscribers - six times more than in the year 2000 (The Communication Initiatives, n.d.).

Given the proliferation of cellular mobile telephone use across all sectors of Filipino society, it is becoming increasingly evident that this highly mobile form of technology and its infrastructure can be leveraged to deliver flexible educational opportunities to more and more Filipinos. In other words, simple, low-cost cellular mobile telephones are now helping Filipinos bridge the once formidable digital divide.

There are wide variations in ICT used in ODL institutions around the world. Further, specific applications and combinations of these applications are very much shaped by the context of their target user populations. In the Philippines, the various ways and means in which ICTs are used include: 


\section{Delivering instructional content}

Depending on learner needs and appropriate pedagogy, instructional contents are packaged in various formats using different media. As mentioned, the development of ODL in the Philippines witnessed instructional packages delivered in print, audiotapes, videotapes, and CD-ROMs. In recent years, going online has made Web-enhanced teaching and learning possible, using rich online resources to supplement and update instructional materials.

To take advantage of high cellular phone use in the Philippines, various initiatives are underway to make use of mobile technologies for education. One such initiative is the University of the Philippines' Open University m-Learning program, launched in 2004. Using a combination of print and mobile materials, UP offered:

From Head to Toe: Body Idioms, a lesson about common idiomatic expressions using the different parts of the body and their meaning

Mental Math, a lesson about simple mathematical operations involving the calculation of large numbers without need of a calculator, pen, or paper

Eating Matters, a lesson on proper nutrition

Lifestyle Check, which offers tips on how to live a healthy lifestyle

Correct Spelling, a lesson on commonly misspelled words

Let's Get Physical, a lesson on exercise to stay fit and healthy

These pilot lesson topics were selected, because they are universally relevant and can benefit all Filipinos, and because they do not culminate in a final examination that could impact students' grades.

Other academic institutions, however, have explored the potential of mobile devices such as cell phones for education purposes. These initiatives tend to be geared towards the augmenting their traditional face-to-face instructional offerings. Such is the case of the text2teach project of the Department of Education, which integrates digital satellite broadcasts and mobile phone communications, to deliver science materials via video broadcast directly from the classroom (Domingo, 2006). The Advanced Science and Technology Institute of the Department of Science and Technology has also been experimenting with Bluetooth technology to connect various personal devices in close proximity to each other. Such research and development initiatives are now leading to new and potential avenues of further research, which educators must explore in their quest to provide learners with more innovative and practical methods of delivering education at a distance. However, while there is clearly potential for mobile devices (such as cell phones), some limitations do exist. Mobile phones can only handle so much information, particularly given that capacity of mobile phone models currently in use. The level and cost of synchronous interactions is also a factor, which can be prohibitive for some potential students. In sum, although the use of cell phones is ubiquitous in the Philippines, using cellular technology for mobile learning does have limitations, which must both be recognized and dealt with accordingly. 


\section{Delivering Support Services to DE Learners}

The success of DE learners depends on the various support services available to them. Moreover, the delivery of student support services must be congruent with the mode of delivering instructional content. Support services like tutorials, library, guidance and counseling, and academic and administrative consultations, must be available in a wide variety of forms, such as online and via SMS. This is very important because many Filipinos do not have easy and ready access to the Internet. As mentioned, cellular phone technology is proving to be an indispensable tool. For instance, SMS can be used for vital communications, such as alerting students that their course materials are ready and that they must make the effort to download these materials from the university website (i.e., from an Internet café).

Communication between and among students can also be facilitated by mobile phone technology. Use of cellular phones can facilitate 'cohort socialization' or can serve as a support mechanism to encourage students along in their DE studies. Socialization via cell phones can provide that much needed thwart feelings of isolation, and promote their 'sense of belonging,' psycho-social aspects that were typically missing in older generations of DE.

\section{Research and Development Work}

Research and development is integral to the informed use of ICT for education. However, aside from being the subject of research itself, ICTs can also be used to gather much needed data on geographically distributed subjects such as students, university staff in the learning centers, etc. Put simply, surveys are now being conducted online, via email, via online interviews using VOIP or Skype or other forms of audio and videoconferencing. Collecting and analyzing data is also being automated using appropriate software for data analysis. Survey questionnaires can be downloaded and submitted online and tabulation of data gathered can be automatically integrated and analyzed with statistical software.

\section{Performing Management and Administration Functions}

ICT has influenced the delivery of instructional content and student support services and has transformed the management of DE institutions. Although most are online, many ODL universities choose to maintain their physical presence locally and internationally. Such 'physical presence' is typically manifest in their learning and testing centers. Use of ICT has clearly become central in facilitating and coordinating communication and activities between and among ODL institutions' widely dispersed service and academic units. Indeed, specific applications to facilitate administrative processes underway in ODL institutions in the Philippines include:

\section{Document Tracking System (DTS) for application for admission}

Through this DTS system, students can submit their applications online, receive acknowledgement of receipt, track the progress of their application, and receive results of their evaluation online. Moreover, because much of these administrative processes are now fully automated, students have access to more efficient, cost-effective services. Currently, UP is conducting research and development on the use of mobile phones for these processes. 


\section{Online registration system}

The online registration system allows the student to enroll in courses at their own convenience, typically during the prescribed registration period. A parallel, traditional registration system is also available for those who do not have access to the Internet or do not own a cell phone.

\section{Online submission of grades}

The online grades submission system enables instructors to submit students' grades online. This system is especially useful for adjunct UP faculty members who work external to UP. Online access to official student enrolment lists are also available, where instructors can post students' interim and final grades for immediate release to students.

\section{Digitization of student records}

Many universities are now using digital student records. Indeed, a typical student accumulates a variety of records over his or her academic lifetime. Clearly, the storage of physical records not only takes up a lot of space, it can take a lot of time and effort, not to mention lead to nightmares as one seeks to retrieving archived student files.

\section{Orientation of new/ incoming Students}

In a DE system, especially in the Philippines wherein many learners consider themselves to be semi-literate and have not been formally exposed to the DE culture of 'independent learning,' student orientation sessions have become imperative for student induction into DE and its process. For instance, orientation activities are required to inform students about course prerequisites, course outlines, procedures for adding and withdrawing from classes, grading criteria, tips on where to access study materials, and so forth. The fact that many students live far away from main and satellite campuses, however, makes it very impractical - if not impossible to gather them physically all in one location for orientation. The creative use of low-cost, readily available technologies like Yahoo Messenger for instance, has helped DE providers overcome obstacles of time and space and levels of synchronous communication and interaction necessary to conduct viable orientation sessions.

\section{Extend the culture of discussion and debate to enhance critical and higher order thinking}

Discussions and debates are central in the development of critical- and higher-order thinking skills, especially among graduate students. In the case of the University of the Philippines, its established culture of 'discussion and debate' should ideally be extended to its DE students. To support debate and discussion among its DE and traditional students, UP's physical classrooms can be linked to its DE students using low-cost, widely available technologies such as Skype, Yahoo Messenger, and so forth. These same technologies can also be used for 'enrichment activities,' such as chat and discussion sessions with subject matter experts. 


\section{Enculturation and Promotion}

In the Philippines, DE is often still perceived as a second-class form of education. This is likely because almost everyone involved in DE, either closely or on the periphery, is somehow a product of the conventional educational system. As such, many Filipinos - albeit wrongly perceive DE to be nothing more than 'correspondence school.' Because most Filipinos lack of correct information on DE, their misguided perceptions contributes to a generalized reification of misguided perceptions across all levels of Filipino society. Disseminating fully informed, research-based evidence about the benefits of DE can help correct this misperception. Put simply, broader and more targeted dissemination of DE research results can help to,

- Rally policy makers and resource providers to support DE

- Enhances DE's credibility in the eyes of industry and other groups whose personnel may benefit from DE, or conversely, may hire graduates of DE programs

- Secure funding for academic institutions seeking to use DE modalities to reach student populations previously unattainable

Given that most academic institutions have finite financial resources, however, money needed to promote, support, and sustain DE enculturation is simply not there or must be shared. Put simply, DE often must take the backseat and remains last on a long list of pressing priorities. As a result, many institutions must share their limited resources to promote their DE offerings. Currently, most DE promotional activities take place online via universities' main websites, homepages dedicated to its DE faculty, publishing and making DE research papers available, publishing eNew stories on DE, SMS broadcasts, etc. As a result, ICTs have been helpful in getting the message out there, helpful in DE 'image building.' In short, use of ICT ensures the greater likelihood of DE reaching its target market, specifically those seeking flexible certificate, degree, and non-degree programs delivered at a distance.

\section{Ensuring Quality Education in a Technology-Driven Mode of Learning}

Quality of DE has always been contentious. Detractors of distance education, somehow equate quality of DE with that of physical face-to-face traditional education in the classrooms. This viewpoint, however, is like comparing apples to oranges - both are fruit, but both are very different. Nonetheless, perceptions need to be based on reality. This means it is necessary to employ the 'quality circle' approach in developing DE courses and learning materials. The 'quality circle' consists of the course writer (who is a subject matter expert), a subject matter specialist (another subject matter expert who peer reviews the soundness of the course and its contents), an instructional designer (who ensures the 'chunking of lessons' is appropriate and that the program/ course goals, contents, and assessments mesh logically with one another), a media specialist (who recommends appropriate delivery mediums), a language editor (who performs copy and substantive editing). In sum, whatever the technology used to deliver instructional content, the ‘quality circle approach' to course development should be standard practice.

Educational providers must strive to use quality and reliable ICT hardware (connections should be available, 24/7) and software (i.e., the LMS). Just as important, these systems must be supported by highly skilled individuals, armed with the knowledge and skills they need to ensure hard and software runs smoothly. To accomplish the human aspect of ICT, institutions must offer training to various user groups (i.e., students, teachers, administrators, etc.). Offering such 
training helps to ensure the efficient and effective use of ICT for all stages of the teaching and learning process, from accessing online classrooms, to course registration, to managing digital library materials, to manipulating databases to get the information one needs to do their work or complete an assignment ... and so forth.

Unfortunately, the common perception among many Filipinos is that DE is an easy way to get a degree. DE, as such, is often seen as a diploma mill. ODL institutions must therefore strive to maintain very high quality standards (i.e., maintaining entrance standards, grading standards, course/program completion standards, and conferment of recognized degrees, etc.). Put simply, institutions offering DE must strictly adhere to the highest standards in terms of setting academic policies and procedures to ensure the integrity of the degrees they confer.

\section{Impact of ICT on ODL in the Philippines}

The influence of ICT on open and distance learning in the Philippines is manifest in many forms. For example, the evolution or development of ODL in the Philippines has clearly been shaped by the use of ICT. Each successive DE generation has been shaped by the dominant technology in use at that particular point in time. As such, adoption and integration of ICT into DE has resulted in new models of learning like m-learning, e-learning, and u-learning.

Education in general has been transformed by the use of ICT. Experts are now talking about the 'School of the Future' (Taylor \& Hogenbirk, 2001), which must grapple with the ever changing needs of Filipinos' increasingly inter-connected, globalized, information-based society. ICT is instrumental in facilitating the shift from "learning as a personal achievement to learning as a result of a global social process” (Taylor \& Hogenbirk, 2001).

The technology used to deliver instructional content has influenced instructional design methods used. While the pedagogy has always been the central consideration, the delivery characteristics of the technology used is also on the minds of instructional designers charged with designing pedagogically sound DE learning materials. The 'chunking of lessons,' for instance, and the level at which learners should interact with the course contents are major design considerations considerations which must fit both the content AND the attributes of the technology. Depending on the technology used, the interaction by which to engage learners will vary. Loveless and Ellis (2001), for example, advise that "it is not enough to use technology to do the same types of activities; educators must also consider the new ways of thinking that the technology affords" (page number for direct quotes please). This means educators must think about pedagogy and ICT from within a systems perspective - not as discrete variables independent from one another.

ICT in use in ODL is also re-shaping universities' entire organizational structures. Westbrook (2001), for example, observed that the introduction of ICTs in education has resulted in the changes in four core areas: 1) curriculum; 2) role of teacher and students; 3) organizational structure; and 4) learning environment. Given that a growing number of transactions now take place online at a distance, appropriately automated systems for recording these transactions, tracking them, keeping and retrieving student records, and so forth, must be supported by holistic policies and procedures that take into account all academic-related activities.

Librero (2006) observed that conventional universities are now using ICTs to achieve 'blended learning' environments, which blend traditional face-to-face classroom delivery with distance delivery. This blended approach has "increased the sources of learning materials that learners must access under blended learning strategies” (Librero, 2006). 
Librero (2006) also noted the changing image of universities as a result incorporating ICT into its educational offerings, a term he calls 'corporatization' (sic). Universities are starting to think and operate like businesses; they are ever seeking to take advantage of emerging opportunities to 'earn lots of money' via online learning.

Use of ICT is also reshaping university cultures. A school's culture is defined by its pattern of relationships and of management of resources. These patterns of relationships and methods of management are, in turn, shaped by its overarching educational philosophy, expectations from the community it serves, its moral culture, political skills of its leadership, and curriculum (Azinian, 2001). In recent years, the culture of teaching has shifted from that of being the 'sage on center stage,' to that of being a learned facilitator, a dynamic called 'learner-centered' pedagogy. Garcia (2002) for example, observed that "online tutors have greater responsibility to ensure that all voices are recognized and respected and must consider all opinions when integrating messages or making concluding statements". Rapatan (2002) further notes that teachers must aim to be "literate in the new technologies and retrain themselves in pedagogy for them to understand how to make technology support conceptual formation and change in students”.

Clearly, the culture of learning has shifted from the culture of students passively listening in a classroom where attendance matters, to the culture of proactive reading, encoding and decoding anytime, anywhere. Garcia (2002) also observed that online discussion has had a democratizing effect on the learning process, a dynamic referred to as an "egalitarian environment" (Brown, 1997, as cited in Garcia, 2002). In an online learning environment, adult learners must take greater responsibility over their own learning paths by sharing their vast array of experiences and knowledge with others in their class.

School administrators must also make the effort to redirect and lead their organization as a "learning organization and review and articulate new performance standards" (Rapatan, 2002).

The growth of ICT in education has given rise to new concepts and realities that are only now becoming mainstream. The concept of 'socialization' in DE settings, for instance, is often technology-mediated and for many students, the only mode of socialization available to them. Time and space ceased to matter in terms of social and transactional distances. The concept of the 'teacher' has fundamentally challenged to include various elements like tutors, LMSs, technical support, learning packages - all further evidence of ICTs influence in education.

\section{Lessons Learned}

First, those seeking to deploy DE must ensure that any technology used is both pedagogically sound and socially-driven. In other words, it is not wise to use technology simply for technology sake, it must be 'relevant.'

'Relevance' in this case has two dimensions: the first is process and the second is substance. Kling (2001) asserts that design and implementation processes must be relevant to the actual social dynamics of a given site of social practice, and that the substance of design and implementation - specifically the actual designs and the actual systems - must be relevant to the lives of the people in which they affect. Kling also said:

Technical work, more superficially, should draw attention to functionalities that people value and more fundamentally, should articulate those analytical categories that have been found useful in describing social reality. 
The cost will always be a consideration, however. A fact that has been implied by Bates (2000) who advised that institutions must comprehend the costs of using new technologies. These costs not only must cover the purchase of the technology (e.g., hardware and software) it must cover the cost of training staff so they can acquire the needed skills and knowledge to use the new technologies effectively, or if that is not feasible, securing funds to hire additional staff that possess the needed skills and knowledge.

Access and cost of access must be attainable and affordable for students. While universities can always find ways to make DE technologies available to its staff and personnel, students must also be considered in the costing equation of 'access'. The cost using ICT, such as the cost of Internet access, cost of sending SMS, or cost of the mobile telephone itself, must be considered when selecting technologies to support DE. Another consideration is that those using this technology should ideally have the skills and knowledge necessary to use the technology effectively.

Partnerships and collaboration are strategies that can work to reduce costs associated with DE. Resources tend to be limited and few institutions of higher education have everything they need to implement quality DE. For instance, there may be cases when the R\&D associated with the development of DE projects is best shared across two or more universities. Moreover, as technologies converge, organizations must respond with common goals and objectives. In this context, collaborations can reduce costs associated with designing and implementing commonly used DE platforms and courses (i.e., sharing of reusable learning objects housed in a common repository). Moreover, collaborations often serve as an enriching learning experience for all involved, such as was the case of UP Open University's collaboration with the University of Singapore to in the design of the Integrated Virtual Learning Environment. UP Open University has similarly collaborated with other governmental institutions for the provision of alternate, back-up forms of Internet connectivity.

Implementation of new teaching and learning strategies also requires attendant changes in organizational structures, such as new units and/ or integration of existing units dedicated to the production of DE learning materials. Such changes in organizational structure, however, must be supported by revised policies and procedures that takes into account all units, both old and new, involved.

Research and evaluation is important. As with any new initiative, the research component of DE projects must inform the selection and subsequent use of any new technology. Projects, therefore, must set goals, means to meet those goals, which must be monitored to ensure their effectiveness and efficiency in meeting those goals.

Introducing innovations always have cost implications. UP's Open University, like most universities, has limited resources upon which to research, design, implement, and support DE. Moreover, any innovation - including DE - has a corresponding cost on some other part of the organization. Often there is simply not enough money to go around. As such, organizations like UP's Open University must beware of reinventing the wheel (i.e., embarking on costly, custom designed systems) and instead seek to creatively use technologies that are already readily available. 


\section{References}

Azinian, H. (2001). Dissemination of information and communications technology and change in school culture. In A. Loveless \& V. Ellis (Eds.) ICT, Pedagogy, and the Curriculum (pp. 35-41). London: Routledge Falmer.

Bates, A. W. (2000). Managing Technological Change: Strategies for college and university leaders. San Francisco: Jossey-Bass.

The Communication Initiatives (n.d.). World Bank Report: Information and Communications for Development 2006, Global Trends and Policies. Retrieved March 12, 2007 from: http://www.comminit.com/trends/ctrends2006/trends-290.html

Domingo, Z. (2006). Text2teach : An ICT-based strategy to help improve quality education in the Philippines. Paper presented in the National Conference of the Philippine e-Learning Society. 28-29 November 2006. Diliman, Quezon City, Philippines.

Flor, A. (1995). Broadcast-based distance learning systems. Diliman, Quezon City: University of the Philippines Press.

Garcia, P. (2002). Tutoring R\&D Management: A case in e-learning. Paper presented in the National Conference of the Philippine e-Learning Society. 1-2 August 2002. Manila.

Kling, R. (2001). What is social informatics? Center for Social Informatics, Indiana University website. Retrieved March 14, 2007 from: http://rkcsi.indiana.edu/

Librero, F. (2006). Trends in e-learning of interest to educators. Paper presented in the National Conference of the Philippine e-Learning Society. 28-29 November 2006. Diliman, Quezon City, Philippines.

Loveless, A., \& Ellis, V. (2001). Something old, something new... Is pedagogy affected by ICT? In A. Loveless and V. Ellis (Eds.) ICT, Pedagogy, and the Curriculum (pp. 63-83). London: Routledge Falmer.

Metropolitan Times (31 December 2003). e-Learning in the Philippines.

Rapatan, M. (2002). Synergizing technology with cognition and pedagogy: A framework for designing e-learning programs. Paper presented in the National Conference of the Philippine e-Learning Society. 1-2 August. Manila.

Taylor, H., \& Hogenbirk, P. (2001). Information and Communication Technologies in Education: The School of the Future. Amsterdam: Kluwer.

The Communication Initiatives (n.d.) The Communication Initiative website. Retrieved March 14, 2007 from: http://www.comminit.com/trends/ctrends2006/trends-290.html

Tibay, H. S. (2004). Paper presented to the Korean Agency for Digital Opportunity and Promotion, October 2004. Seoul, Korea, 
Westbrook, J. (2001). The Esloo design for the digital elementary and secondary education. In A. Loveless and V. Ellis (Eds.) ICT, Pedagogy, and the Curriculum (55-70.). London:

Routledge Falmer.

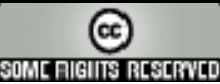

